\title{
Evaluation of hepatoprotective potential of aqueous extract of Withania somnifera in albino rats
}

\author{
Monica Sharma, Anand Gaur*, Pinki Vishwakarma, Raj Kumar Goel, K. K. Saxena
}

Department of Pharmacology, LLRM Medical College, Meerut, Uttar Pradesh, India

Received: 14 January 2021

Revised: 28 January 2021

Accepted: 30 January 2021

\section{*Correspondence:}

Dr. Anand Gaur,

Email: drgaur49anand@gmail.com

Copyright: () the author(s), publisher and licensee Medip Academy. This is an open-access article distributed under the terms of the Creative Commons Attribution Non-Commercial License, which permits unrestricted non-commercial use, distribution, and reproduction in any medium, provided the original work is properly cited.

\begin{abstract}
Background: Hepatic diseases are a major cause of morbidity and disability of work force throughout the world. The treatment of hepatic diseases with standard drugs poses the risk of toxicity on various organ systems. Withania somnifera, a herbal plant has been claimed to be effective in the treatment of various types of hepatic conditions. The present study was undertaken to explore the hepatoprotective activity of aqueous extract of Withania somnifera (AEWS) in experimentally induced hepatotoxicity in albino rats.

Methods: The study was commenced after obtaining approval from institutional animal ethical committee using AEWS leaves in Albino wistar rats (150-200 gm) of either sex. The hepatoprotective activity was evaluated using biochemical examination. The animals were divided into five groups of six animals each. In each experiment, first group was given normal saline $(1 \mathrm{ml} / \mathrm{kg} / \mathrm{day})$, second group was injected with toxin $\mathrm{CCl}_{4}(1 \mathrm{ml} / \mathrm{kg})$ i.p only once to produce hepatotoxicity, third and fourth groups were given Withania somnifera orally (500 mg/kg and $1000 \mathrm{mg} / \mathrm{kg}$ ) (respectively), as a single dose per orally every morning and fifth group was given standard drug Liv-52 (1 mg/kg).

Results: Aqueous extract of Withania somnifera leaves in oral dose exhibited significant hepatoprotective effect in all models used in this study.

Conclusions: It can be concluded from our study that aqueous extract of Withania somnifera leaves possesses hepatoprotective activity.
\end{abstract}

Keywords: Hepatoprotective, Albino rats, Withania somnifera, Carbon tetrachloride

\section{INTRODUCTION}

The liver is essential for maintenance of normal metabolic homeostasis as it carries out detoxification and metabolism of various toxins and drugs by its metabolizing enzyme system. Various microbial infections, drugs, toxins, nutritional and metabolic diseases may disrupt the normal function and structural integrity of liver. Various xenobiotics are known to cause hepatotoxicity, one among them is carbon tetrachloride $\left(\mathrm{CCl}_{4}\right)$ that may cause liver damage by lipid peroxidation (LP). ${ }^{1,2}$
Till now only supportive measures are employed for liver disorders in modern medicine as its armamentarium lacks any drug which is useful to treat or prevent liver diseases.

India, with its wealth and variety of medicinal plants, has accumulated a great mass of popular remedies for liver ailments in the indigenous ayurvedic system of medicine, many of which are in common use even today. There has been a sharp upward trend in the use of phytomedicines over the last decades in Europe and USA. ${ }^{3,4}$ The recent trend, however, in the treatment of liver ailments, is the 
use of formulations which contain more than one medicinal plant. Some formulations have been established as hepatoprotective agents both in experimental as well as clinical studies.

A plant Withania somnifera in supposed to have hepatoprotective action. The root of $W$. somnifera, known as Indian ginseng (ashwagandha), has been described in ayurvedic folk medicine to have potent aphrodisiac, sedative, and energy-enhancing tonic properties. ${ }^{5}$ Many investigators have reported that $W$. somnifera possesses anabolic, antiserotonergic and anticancer activities. Moreover, it is beneficial in the treatment of arthritis, geriatric problems, stress, and male sexual dysfunctions. It also has adaptogenic, cardiotropic, cardioprotective, and anticoagulant properties. ${ }^{6} \mathrm{~W}$. somnifera has been shown to inhibit LP in stress-induced animals. ${ }^{7}$ The proven activities of $W$. somnifera as adaptogenic, antiinflammatory, antioxidant, anti-platelet, antihypertensive, hypoglycemic and hypolipidemic may also contribute to its cardioprotective properties. ${ }^{8}$

The current study was designed to investigate the potential hepatoprotective effect of W. somnifera in $\mathrm{CCl}_{4}$ induced hepatotoxicity and liver damage in rats.

\section{METHODS}

\section{Animals}

Healthy Albino wistar rats of either gender, weighing 150-200 g were obtained from CPCSEA approved central animal house of LLRM medical college. The selected rats were housed in polypropylene cages under controlled conditions of temperature $\left(25^{\circ} \mathrm{C}\right)$ and alternating periods of light and darkness of 12 hours each. The rats had free access to standard pellet diet and tap water ad libitum. After one week of acclimatization, the animals were rendered suitable for study. Pregnant female rats were not included in the study.

\section{Preparation of plant extract}

Leaves of Withania somnifera were obtained and allowed to dry under the shade. Thereafter $50 \mathrm{~g}$ of dry powdered leaves were boiled in $250 \mathrm{ml}$ of water for half an hour. This solution was left to stand for 24 hours. Next day the solution was filtered and evaporated to obtain dry extract. This dried extract was further powdered and then stored at $0-4^{0} \mathrm{C}$. When needed the extract was suspended in water to achieve a concentration of $1 \%$.

\section{Drugs and chemicals}

Sources of drugs and chemicals used in current investigation were; Liv-52 (Himalaya drug company), Ketamine (Kawality pharmaceuticals) and Diazepam (Watson pharma).

\section{Experimental design}

Animal were divided into five groups of six animals each.

Group I: As control group was administered normal saline $(0.9 \% \mathrm{NaCl}$ solution) in a single oral dose of 1 $\mathrm{ml} / \mathrm{kg} /$ day for 21 days.

Group II: In addition to pellet diet and tap water, this group was injected with toxin $\mathrm{CCl}_{4}(1 \mathrm{ml} / \mathrm{kg})$ i.p only once to produce hepatotoxicity on $21^{\text {st }}$ day.

Group III and group IV: These groups were given Withania somnifera in two different doses (500 and 1000 $\mathrm{mg} / \mathrm{kg}$ ) (respectively) as a single dose per orally every morning for 21 days followed by an injection of $\mathrm{CCl}_{4}(1$ $\mathrm{ml} / \mathrm{kg}$, i.p.) on 21 st day. $^{9}$

Group V: This group received Liv.52 (1mg/kg/day) orally for 21 days followed by an injection $\mathrm{CCl}_{4}$ (1 ml/kg i.p.) on $21^{\text {st }}$ day. Withania somnifera was administered by gavage method with animals fasted 3-4 hours prior to and 1 hour after administration of test drugs to ensure proper absorption. After administration of $\mathrm{CCl}_{4}$, animals of all the groups were fasted for 24 hours although water remained freely available during this period. Thereafter animals were sacrificed under ketamine $(75 \mathrm{mg} / \mathrm{kg})$ and diazepam $(10 \mathrm{mg} / \mathrm{kg})$ anaesthesia given intraperitoneally.

${ }^{10}$ Blood samples were collected from abdominal aorta for performing liver function tests which included total bilirubin, alanine transaminase (ALT), alkaline phosphatase (ALP) and albumin.

\section{Statistical analysis}

The data obtained was expressed as mean \pm SD. It was calculated for each group to observe the general trend of the group. Significant differences between groups were calculated by the application of Post Hoc Tukey's test. Pvalues were estimated by referring to appropriate tables. ${ }^{11}$ $\mathrm{p}<0.05$ was considered as statistically significant.

\section{RESULTS}

It was observed that aqueous extract of Withania somnifera offered hepatoprotection in dose dependent fashion as reflected by significant improvement in all biochemical studies (Table 1). In the higher dose studied for Withania somnifera, i.e. $1000 \mathrm{mg} / \mathrm{kg}$, the protection was found to be comparable to the response offered by Liv.52.

\section{Effect on alanine aminotransferase (ALT)}

With Withania somnifera there is limitation of ALT rise after $\mathrm{CCl}_{4}$ administration. In dose of $1000 \mathrm{mg} / \mathrm{kg}$ for 21 days the Withania somnifera extract had much efficacy, in limiting the ALT rise after $\mathrm{CCl}_{4}$ administration, to $140.2 \pm 12.1 \mathrm{IU} / \mathrm{l}$, which was highly significant (Table 1 ) $(\mathrm{p}<0.001)$. 


\section{Effect on alkaline phosphatase (ALP)}

With Withania somnifera there is limitation of ALP rise after $\mathrm{CCl}_{4}$ administration. In dose of $1000 \mathrm{mg} / \mathrm{kg}$ for 21 days the Withania somnifera extract had much efficacy, in limiting the ALP rise after $\mathrm{CCl}_{4}$ administration, to 204.8 \pm 24.42 IU/L, which was highly significant (Table 1) $(\mathrm{p}<0.001)$.

\section{Effect on total serum bilirubin}

With Withania somnifera there is limitation of Total Bilirubin rise after $\mathrm{CCl}_{4}$ administration. In dose of 1000 $\mathrm{mg} / \mathrm{kg}$ for 21 days the Withania somnifera extract had much efficacy, in limiting the Total Bilirubin rise after $\mathrm{CCl}_{4}$ administration, to $0.52 \pm 0.64 \mathrm{IU} / \mathrm{L}$ which was highly significant (Table 1$)(\mathrm{p}<0.001)$.

\section{Effect on albumin}

There was no such difference in serum Albumin levels and all the measurement recorded were in normal range. The Albumin levels varied from $5.1 \pm 0.76 \mathrm{gm} / \mathrm{dl}$ to $5.2 \pm 0.31 \mathrm{gm} / \mathrm{dl}$ showed no correlation, which was insignificant (Table 1) $(\mathrm{p}>0.05)$.

Table 1: Effect of Withania somnifera in graded doses on carbon tetrachloride induced changes in various biochemical parameters $($ mean \pm SE) $(n=6)$.

\begin{tabular}{|c|c|c|c|c|c|}
\hline Group & Treatment & $\begin{array}{l}\text { Alanine } \\
\text { transaminase } \\
(\text { IU/L) }(\text { mean } \pm \text { SE })\end{array}$ & $\begin{array}{l}\text { Alkaline phosphatase } \\
\text { (IU/L) (mean } \pm \text { SE) }\end{array}$ & $\begin{array}{l}\text { Total bilirubin } \\
\text { (IU/L) }(\text { mean } \pm \text { SE) }\end{array}$ & $\begin{array}{l}\text { Albumin } \\
(\text { gm/dl) } \\
(\text { mean } \pm \text { SE })\end{array}$ \\
\hline I & $\begin{array}{l}\text { Normal saline } \\
(1 \mathrm{ml} / \mathrm{kg})\end{array}$ & $29.5 \pm 3.35$ & $73.9 \pm 4.63$ & $0.25 \pm 0.95$ & $4.6 \pm 0.82$ \\
\hline II & $\mathrm{CCl}_{4}(1 \mathrm{ml} / \mathrm{kg})$ & $433.5 \pm 48.67$ & $600.42 \pm 52.9$ & $2.03 \pm 0.86$ & $5.3 \pm 0.92$ \\
\hline III & $\begin{array}{l}\text { Withania } \\
\text { somnifera } \\
(500 \mathrm{mg} / \mathrm{kg})\end{array}$ & $304.9 \pm 36.03^{\mathfrak{f}}$ & $382.1 \pm 42.62^{£}$ & $0.80 \pm 0.53 *$ & $5.14 \pm 0.88$ \\
\hline IV & $\begin{array}{l}\text { Withania } \\
\text { somnifera } \\
(1000 \mathrm{mg} / \mathrm{kg})\end{array}$ & $140.2 \pm 12.1^{\wedge}$ & $204.8 \pm 24.42^{\wedge}$ & $0.52 \pm 0.64^{\wedge}$ & $5.1 \pm 0.76$ \\
\hline $\mathbf{V}$ & $\begin{array}{l}\text { LIV.52 } \\
(1 \mathrm{mg} / \mathrm{kg})\end{array}$ & $140.7 \pm 8.1^{\wedge}$ & $198.9 \pm 11.6^{\wedge}$ & $0.46 \pm 0.42^{\wedge}$ & $5.2 \pm 0.31$ \\
\hline
\end{tabular}

${ }^{£} \mathrm{P}<0.05$ as compared to $\mathrm{CCl}_{4}$ treated group, ${ }^{*} \mathrm{p}<0.01$ as compared to $\mathrm{CCl}_{4}$ treated group, ${ }^{\wedge} \mathrm{p}<0.001$ as compared to $\mathrm{CCl}_{4}$ treated group.

\section{DISCUSSION}

Liver damage is always associated with cellular necrosis, increase in tissue LP and depletion of reduced liver glutathione. In addition, elevated levels of hepatic serum enzymes are indicative of cellular leakage. ${ }^{12}$ Among xenobiotics, $\mathrm{CCl}_{4}$ represents the main cause of acute liver injury through its bioactivation to trichloromethyl free radicals that cause LP and produces hepatocellular damage. ${ }^{13,14}$ In the present study, $\mathrm{CCl}_{4}$ induced severe liver damage as evidenced by the significant elevation of serum levels of ALT, ALP and total bilirubin. ${ }^{15}$ These effects were coupled with a marked hepatic oxidative stress as indicated by histopathological changes demonstrating liver injury. In previous studies, oxidative stress was evidenced by decreased glutathione (GSH) liver tissue content as well as decreased superoxide dismutase (SOD), glutathione peroxidase (GPx), glutathione reductase (GR) and glutathione-S-transferase (GST) activities coupled with the increased production of malondialdehyde (MDA). It is well known that GSH is a major non-enzymatic antioxidant and plays an important role in cellular defense, which is a crucial determinant of tissue susceptibility to oxidative damage. ${ }^{16,17}$
During the radical stress, GSH is oxidized by GPx to oxidised glutathione, which can then be reduced back to GSH by GR. Reduced glutathione is also a cofactor for GST, primarily involved in the detoxification of electrophilic xenobiotics via catalysing the formation of GSH-electrophile conjugate. ${ }^{18-20}$ In addition, SOD catalyses the dismutation of superoxide anion to $\mathrm{H}_{2} \mathrm{O}_{2}$ and $\mathrm{O}_{2}$. Because $\mathrm{H}_{2} \mathrm{O}_{2}$ is still harmful to cells, catalase and GPx further catalyse the decomposition of $\mathrm{H}_{2} \mathrm{O}_{2}$ to water. ${ }^{20}$ The increase in MDA levels, suggests enhanced LP leading to tissue damage and failure of antioxidant defense mechanisms to prevent formation of excessive free radicals. ${ }^{21}$

Treatment with $W$. somnifera improved the liver function, an effect that was evidenced by the significant reduction in ALT, ALP and total bilirubin. This improvement of liver function, in W. Somnifera treated groups, was also supported by histopathological examination which revealed amelioration of pathological changes observed in $\mathrm{CCl}_{4}$-treated group. The possible mechanism of the hepatoprotective effect of extracts may be, in part, attributed to their antioxidant activities. As demonstrated in previous studies the significant increase in the GSH tissue content and decreased GPx activity in $W$. 
somnifera, treated groups can be attributed to withanolides, which are the main active constituents $(2.8 \%)$ in W. somnifera. ${ }^{22}$ Moreover, the herb root has been found to contain antioxidants, and therefore the herb root has been used to treat various diseases like stress, anxiety, insomnia, arthritis and neurodegeneration. ${ }^{23-26}$

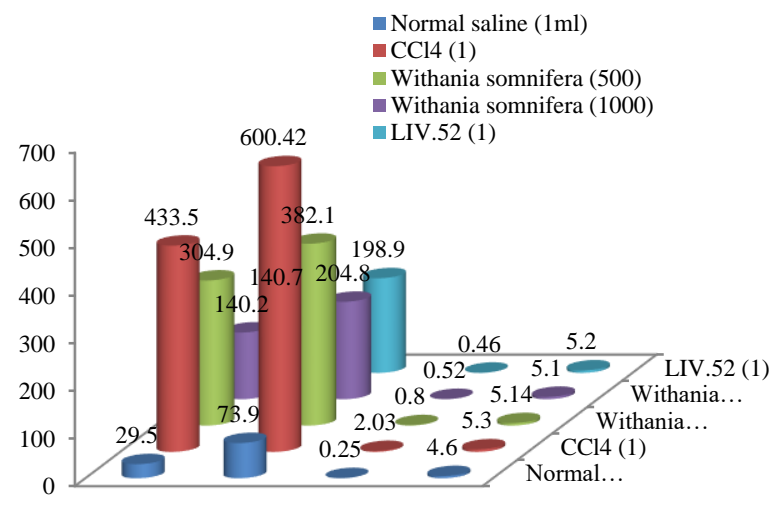

Figure 1: Effect of Withania somnifera in graded doses on carbon tetrachloride induced changes in various biochemical parameters $($ mean \pm SE) $(n=6)$.

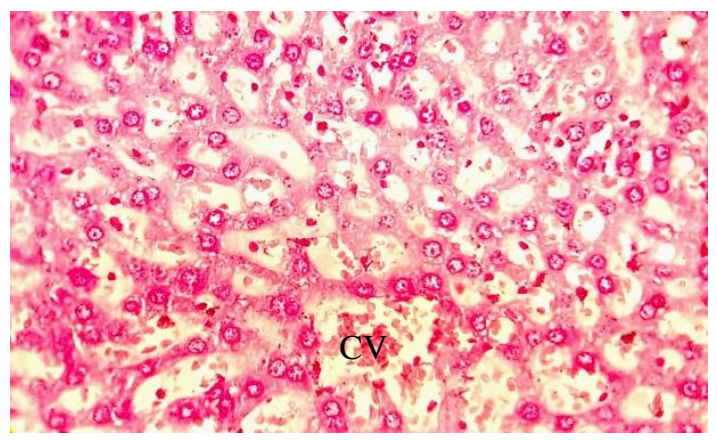

Figure 2: Microscopic feature of the liver, in normal saline treated group. (Normal hepatic lobule architecture is seen. Hepatocytes and their nuclei are well visible; $H \& E$ stain, $400 \mathrm{X}, \mathrm{CV}$ : central vein).

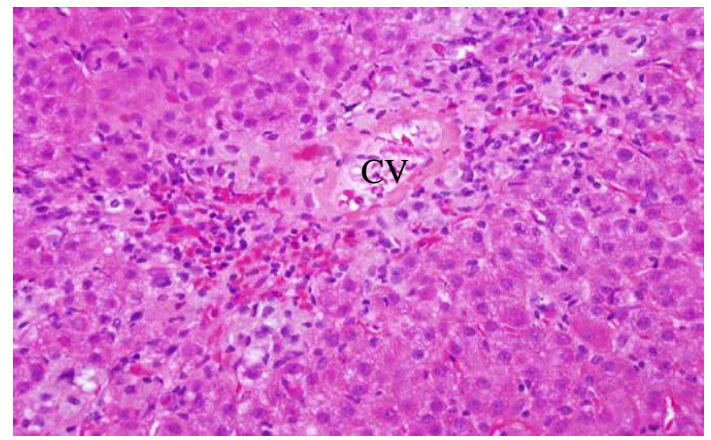

Figure 3: Microscopic feature of the liver in $\mathrm{CCl}_{4}$ treated group. (Extensive centrizonal necrosis is seen. Only cellular debris is seen and no hepatocytes with nuclei are discernible, H\&E stain 400X).

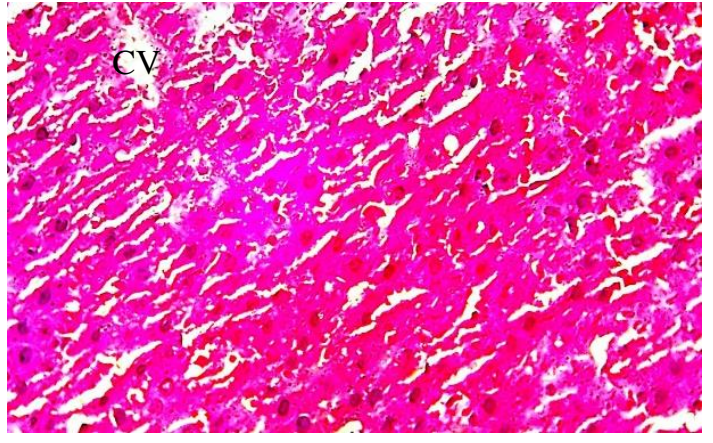

Figure 4: Microscopic feature of the liver of animals in Withania somnifera $(500 \mathrm{mg} / \mathrm{kg})$ treated group.

(Centrizonal area is conspicuous by the presence of hepatocytes, showing minimal fatty changes. Necrosis is not seen, $\mathrm{H} \& \mathrm{E}$ Stain $400 \mathrm{X}$ ).

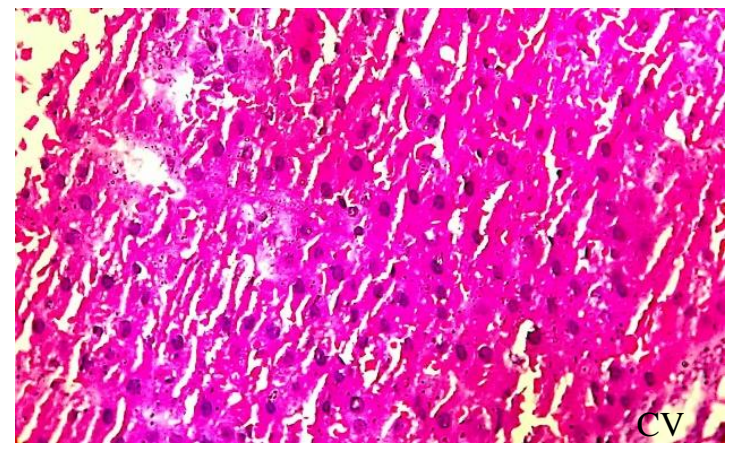

Figure 5: Microscopic feature of the liver of in Withania somnifera $(1000 \mathrm{mg} / \mathrm{kg})$ treated group. (Constricted sinusoids are seen indicating mild hepatocyte swelling. Necrosis is not seen. H\&E stain 400X).

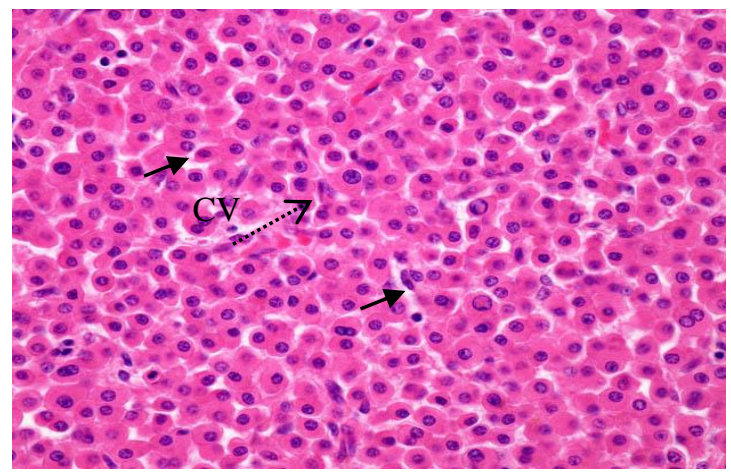

Figure 6: Microscopic feature of the liver in Liv. 52 treated group. (Mild hepatocyte swelling is present as indicated by constrcited sinusoids. Inflammatory cells are seen mostly around central vein, H\&E stain 400X, solid arrows: sinusoids, dotted arrows: inflammatory cells).

\section{Limitations}

Animal model of disease does not exactly represent the real disease in human beings so further clinical studies 
should be conducted. Though ideally both the doses of $W$. somnifera should be chosen in combination with aqueous extract, only higher dose of $W$. somnifera was chosen (to reduce the number of animals). As this study was of short duration and evaluated only treatment of disease, other studies of longer duration need to be planned to explore the preventive role of $W$. somnifera in hepatotoxicity.

\section{CONCLUSION}

Results of current investigation support the possible antihepatotoxic effect of $W$. somnifera extracts against $\mathrm{CCl}_{4}$-induced hepatotoxicity in rats. This antihepatotoxic effect may be attributed partially to their antioxidant activity. However, further pharmacological evidence at the molecular level is required to establish the actual mechanism of the action of the drug and research into this area is underway.

\section{ACKNOWLEDGEMENTS}

Authour are thankful to Dr. Ganesh Singh, (statistician), department of community medicine, LLRM medical college, Meerut, for his cooperation and sincere help in this study.

\section{Funding: No funding sources}

Conflict of interest: None declared

Ethical approval: The study was approved by the Institutional Ethics Committee

\section{REFERENCES}

1. Jan AT, Azam M, Siddiqui K, Ali A, Choi I, Haq QM. Heavy metals and human health: mechanistic insight into toxicity and counter defense system of antioxidants. Int J Mol Sci. 2015;16(12):29592-630.

2. Demirdag K, BakceciogluIH, OzercanIH, Ozden M, Yilmaz S, Kalkan A. Role of L-carnitine in the prevention of acute liver damage induced by carbon tetrachloride in rats. J Gastroenterol Hepatol. 2004; 19:333-8

3. Ernst E. The role of complementary and alternative medicine. Brit Medi J. 2000;321:1133-5.

4. Kessler RC, Davis RB, Foster DF, Van Rompay MI, Walters EE, Wilkey SA, et al. Long-term trends in the use of complementary and alternative medical therapies in the United States. Ann Int Med. 2001;135:262-8.

5. Williamson EM. Major herbs of ayurveda. London: Churchill Livingstone; 2002: 322-323.

6. Misra LC, Singh BB, Degenais S. Scientific basis for the therapeutic use of Withaniasomnifera (ashwagandha): a review. Alt Med Rev. 2000;5:33446.

7. Kaur T, Singh H, Mishra R. Withania somnifera as a potential anxiolytic and immunomodulatory agent in acute sleep deprived female Wistar rats. Mol Cell Biochem. 2017;427:91-101.
8. Ojha SK, Arya DS. Withaniasomnifera Dunal (Ashwagandha): A promising remedy for cardiovascular diseases. World J Med Sci.2009;4: 156-8.

9. Bhattacharya A, Ramanathan $\mathrm{M}$, Ghosal S, Bhattacharya SK. Effect of Withaniasomnifera Glycowithanolides on iron induced hepatotoxicity in rats. Phytother Res. 2000;14:568-70.

10. Wixson SK, White WJ. A comparison of pentobarbital, fentanyl-droperdiol, ketamine-xylazine and ketamine-diazepam anesthesia in adult male rats. LAS. 1987;37(6):726-30.

11. Ghosh MN. Fundamentals of experimental pharmacology. 4th ed. Kolkata: Hilton \& Company; 2008:235-7.

12. Contreras-Zentella ML, Hernández-Muñoz R. Is liver enzyme release really associated with cell necrosis induced by oxidant stress?. Oxid Med Cell Longev. 2016;2016:3529149.

13. Ferreira EA, Gris EF, Felipe KB. Potent hepatoprotective effect in $\mathrm{CCl}$ (4)-induced hepatic injury in mice of phloroacetophenone from Myrcia multiflora. Libyan J Med. 2010;5:10.

14. Poli G. Pathogenesis of liver fibrosis: role of oxidative stress. Mol Aspect Med. 2000;21(3):49-98.

15. Akbartabar TM, Joodi B, Sadeghi H. Hepatoprotective activity of aerial parts of Otostegia persica against carbon tetrachloride-induced liver damage in rats. Avicenna J Phytomed. 2015;5(3): 238-46.

16. El-Bahr SM. Effect of curcumin on hepatic antioxidant enzymes activities and gene expressions in rats intoxicated with aflatoxin B1. Phytother Res. 2015;29(1):134-40.

17. Kaur M, Jindal R. Oxidative stress response in liver, kidney and gills of ctenopharyngodon idellus (cuvier $\&$ valenciennes) exposed to chlorpyrifos. MOJ Biol Med. 2017;1(4):103-12.

18. Kurutas EB. The importance of antioxidants which play the role in cellular response against oxidative/nitrosative stress: current state. Nutr J. 2016;15(1):71.

19. Hasanuzzaman M, Nahar K, Anee TI, Fujita M. Glutathione in plants: biosynthesis and physiological role in environmental stress tolerance. Physiol Mol Biol Plants. 2017;23(2):249-68.

20. Hayes JD, Flanagan JU, Jowsey IR. Glutathione transferases. Annual review of pharmacology and toxicology. 2005;45:51-88.

21. Ayala A, Muñoz MF, Argüelles S. Lipid peroxidation: production, metabolism, and signaling mechanisms of malondialdehyde and 4-hydroxy-2nonenal. Oxid Med Cell Longev. 2014;2014:360438.

22. Scartezzini P, Speroni E. Review on some plants of Indian traditional medicine with antioxidant activity. J Ethanopharmacol. 2000;71:23-43.

23. Russo A, Izzo AA, Cardile V, Borrelli F, Vanella A. Indian medicinal plants as antiradicals and DNA cleavage protectors. Phytomed. 2001;8:125-32. 
24. Gupta SK, Dua A, Vohra BP. Withania somnifera (Ashwagandha) attenuates antioxidant defense in aged spinal cord and inhibits copper induced lipid peroxidation and protein oxidative modifications. Drug Metab Drug Interact. 2003;19:211-22.

25. Kaur P, Sharma M, Mathur S, Tiwari M, Divekar HM, Kumar R, et al. Effect of 1-oxo-5beta, 6betaepoxy-witha- 2-ene-27-ethoxyolide isolated from the roots of Withania somnifera on stress indices in Wistar rats. J Alt Complement Med. 2003;9:897-907.

26. RajaSankar S, Manivasagam T, Sankar V, Prakash S, Muthusamy R, Krishnamurti A, et al. Withania somnifera root extract improves catecholamines and physiological abnormalities seen in a Parkinson's disease model mouse. J Ethanopharmacol. 2009;125: 369-73.

Cite this article as: Sharma M, Gaur A, Vishwakarma P, Goel RK, Saxena KK. Evaluation of hepatoprotective potential of aqueous extract of Withania somnifera in albino rats. Int $\mathrm{J}$ Basic Clin Pharmacol 2021;10:255-60. 